\title{
1 Slip distribution model along the anchorage length of prestressing strands
}

2

J.R. Martí-Vargas ${ }^{1 *}$, W.M. Hale ${ }^{2}$, E. García-Taengua ${ }^{1}$, P. Serna ${ }^{1}$

${ }^{1}$ ICITECH Institute of Concrete Science and Technology, Universitat Politècnica de València, 4G, Camino de Vera s/n, 46022, Valencia, Spain

${ }^{2}$ Department of Civil Engineering, 4190 Bell Engineering Center, 1 University of Arkansas, Fayetteville, AR 72701, United States

e-mail address: jrmarti@cst.upv.es; micah@uark.edu; emgartae@upv.es; pserna@ cst.upv.es;

*Corresponding author: Tel.: +34 963877007 (ext. 75612); Fax: +34 96 3877569;

e-mail address: jrmarti@ cst.upv.es (José R. Martí-Vargas)

\section{Abstract:}

An analytical model to predict strand slips within both transmission and anchorage lengths in pretensioned prestressed concrete members is presented. This model has been derived from an experimental research work by analysing the bond behavior and determining the transmission and anchorage lengths of seven-wire prestressing steel strands in different concrete mixes. A testing technique based on measuring the prestressing strand force in specimens with different embedment lengths has been used. The testing technique allows measurement of free end slip as well as indirect determination of the strand slip at different cross sections of a member without interfering with bond phenomena. The experimental results and the proposed model for strand slip distribution have been compared with theoretical predictions according to different equations in the literature and with experimental results obtained by other researchers.

Keywords: concrete; strand; bond; prestress; transmission length; anchorage length; slip; model 


\section{Introduction}

2

3 The prestressing force is transferred from the prestressing strands to concrete by bond during

4 the prestress transfer operation. Afterwards, bond mechanisms allow force variations in the

5 prestressing strands ranging from zero at the free end of the member to the full prestressing

6 strand force which is achieved at a distance defined as transmission length [1] -or transfer 7 length [2]-.

9 Also, when a pretensioned prestressed concrete member is loaded by externals actions, higher

10 forces in the prestressing strands are activated. This increase in prestressing strand force is 11 developed only if bond between concrete and prestressing strands allows it, and a bond length 12 (complementary bond length [3] -or flexural bond length [2]-) beyond the transmission length is required. The sum of the transmission length and this complementary bond length is defined as anchorage length [1] -or development length [2]-. Fig. 1 shows the idealized prestressing strand force profile according to the aforementioned lengths.

16

17 Variation in prestressing strand force along both transmission and anchorage lengths involves bond stresses which are activated by the relative displacement (slips) of the prestressing strand into concrete cross-sections [4, 5]. After prestress transfer, the maximum strand slip occurs at the free ends of the member, and the strand slip will be zero when the full

21 prestressing strand force is achieved and compatibility of strains between the prestressing 22 strand and concrete exists [6]. In addition to the definition of anchorage length in [1], Buckner 23 [7] indicates that the overloading force must be developed without additional strand end slip 24 at the free ends of the member. 
1 The prestressing strand-to-concrete bond is a function of a large number of factors [8, 9]. A

2 literature review of the factors influencing bond and transmission and anchorage lengths of

3 prestressing reinforcement has been presented in [1]. Several equations to calculate both

4 transmission and anchorage lengths have been proposed [3, 10, 11]. However, knowledge on

5 the slips of prestressing strands is generally limited to free end slip measurements which are

6 used to obtain the transmission length by means of the Guyon's theory [12].

7

8 Consequently, the purpose of this research is to develop an analytical bond model to predict

9 the slip distribution along both the transmission and anchorage lengths of seven-wire $13 \mathrm{~mm}$

10 prestressing steel strands. An experimental program has been carried out to determine the

11 force-slip relationships along the transmission and anchorage lengths for twelve different

12 concrete proportionings by means of the ECADA test method [13].

\section{Background}

The measurement of the free strand end slip is a traditional indirect method to determine the transmission length in pretensioned prestressed concrete members. This method has been proposed as a simple non-destructive assurance procedure by which the quality of bond can be monitored within precasting plants $[14,15]$. Most experimental standards [16-18] are based on this method along with the analysis of the strains profile on the concrete surface

21 after release, but it provides no information on the anchorage length or on the slips along the 22 transmission length.

24 The relationship between the transmission length and the strand end slip can be expressed as 25 [12]: 
$1 \quad L_{t}=\alpha \frac{\delta_{f}}{\varepsilon_{p i}}$

2 where $L_{t}$ is the transmission length, $\delta_{f}$ is the strand end slip at the free end of a pretensioned

3 prestressed concrete member, $\varepsilon_{p i}$ is the initial strand strain, and $\alpha$ represents the shape factor

4 of the bond stress distribution ( $\alpha=2$ for uniform bond stress and $\alpha=3$ for linear descending

5 bond stress distribution). Several experimental and theoretical studies subsequent to Guyon's

6 theoretical analysis have reported $\alpha$ values ranging from 1.5 to 4 , as it has been reviewed in

7 [19]. Also a value of $\alpha=2.44$ for Guyon's equation has been proposed in [19].

8

9 A modification of Guyon's expression was proposed by Balazs [4, 20] which takes into

10 account a nonlinear bond stress-slip relationship over the transmission length considering the

11 strand diameter and concrete compressive strength. As a result, the following equations for

12 calculating the transmission length of $13 \mathrm{~mm}$ seven-wire prestressing steel strand were

13 developed [4, 20]:

$14 \quad L_{t}=105 d_{b} \sqrt[4]{\frac{\delta_{f}{ }^{3 / 2}}{f_{c i}^{\prime}}}$

$16 L_{t}=\frac{111 \delta_{f}^{0.625}}{f_{c i}^{\prime 0.15} \cdot\left(\frac{f_{p i}}{E_{p}}\right)^{0.4}}$

17 where $d_{b}$ is the diameter of prestressing strand, $f_{c i}$ is the concrete compressive strength at the 18 time of prestress transfer, $f_{p i}$ is the strand stress immediately before release and $E_{p}$ is the 19 modulus of elasticity of the prestressing strand.

21 An equation to obtain directly the strand slip at the free end as a function of the initial 22 prestress was also proposed by Balazs [4]: 
$1 \quad \delta_{f}=1.23\left(\frac{f_{p i}^{2}}{E_{p} \sqrt{f_{c i}^{\prime}}}\right)^{0.8}$

2 Another equation that relates the transmission length to the strand free end slip of a

3 pretensioned prestressed concrete member was proposed in [21] $\left(K=0.00035 \mathrm{~mm}^{-1}\right.$ for 12.7

$4 \quad \mathrm{~mm}$ seven-wire strand):

$5 \quad L_{t}=\sqrt{\frac{\delta}{K}}$

6 Regarding the anchorage length, the test methods are based on pull-out tests [22] or full size

7 beams [23]. The former does not reproduce the previous prestress transfer stage, and the latter

8 requires an iterative beam testing process. In this iterative process, there are intrinsic

9 disadvantages due to the size and cost of the members. Other procedures for bond strength

10 determination such as the push-pullout test [24] or the use of cylindrical [25] or prismatic

11 specimens [26] have been used in some cases.

13 To measure slips, Mains [27] devised a technique based on determining the reinforcement 14 strain. This technique involves attaching strain gauges inside specially prepared hollow 15 reinforcement. A large diameter is required, and therefore this technique is not applicable to 16 the wires and strands for pretensioned concrete.

In an experimental study conducted by Ratz et al. [28] on the wire displacements into the concrete along the transmission zones, prestressed concrete specimens were made with holes at various distances at the upper side of specimens. The holes allowed researchers to observe

21 the wires in the specimens. Marks on the wire surface were made. Wire movements relative to concrete at various stages of the prestress transfer were measured using microscopes provided with micrometers eye-glass. The microscopes were attached to the concrete and focused on 
1 the holes. From this study, an empirical relationship between the stress in the wire and its

2 displacement within the transmission zone was determined. However, this method has the

3 disadvantage of removing concrete from the surface of the wires by the holes with the

4 consequent destruction of bond.

6 An experimental application of air-gage devices to detect small linear movements (slips) of

7 reinforcement in concrete slabs and to convert these slips into changes in air-flow rates was 8 developed by Lewis and Moore [29]. In this procedure, a stainless-steel pin is driven into a

9 hole drilled into the reinforcement. A plastic block is then placed over this pin, and the entire 10 assemblage is cast into the concrete. Consequently, the bond phenomenon and the concrete 11 confinement of the reinforcement are distorted.

12

Therefore, the measurement of slips in prestressing reinforcement mothered the application of 14 sophisticated measurement procedures that do not disturb the bond phenomenom.

16 The radiographic strain-measuring technique was applied to measure slips along the 17 transmission length in wires [30]. This technique involves placing small lead markers in slots 18 formed in the reinforcement. The positions of the markers are recorded on an X-ray 19 photograph. Wire slip relative to the concrete may be measured directly as the distance 20 between the portions of a marker embedded in the wire and in the concrete. However, the 21 conditions for obtaining a satisfactory film are critical and this technique has not been 22 developed sufficiently. 
1 Sophisticated techniques for instrumentation and measurement procedures based on fiber

2 optic sensors are being used in some cases [31], but have not been used for strand-concrete 3 bond.

5 Recently, an experimental methodology based on the measurement and the analysis of the

6 force supported by the prestresing strand in specimen series with different embedment lengths

7 has been conceived: the ECADA test method [13, 32]. This test method allows one to 8 determine both transmission and anchorage lengths [33], changes in these lengths with time 9 [34] and prestress losses [35], and the strand slip measurement simultaneously at both ends $10[36]$ of a specimen.

\section{Methodology}

The ECADA test methodology allows the bond characterization of prestressing reinforcement through the sequential release of the prestress transfer (detensioning) and the pull-out (loading) operation on the same specimen test. This test method is based on measuring and analysing the force supported by the strand in a series of pretensioned prestressed concrete specimens with different embedment lengths. Fig. 2 shows the layout of the test equipment. The equipment consists of a pretensioning frame with an adjustable strand anchorage placed in the frame plate corresponding to the free end and an Anchorage-Measurement-Access

21 (AMA) system placed in the frame plate corresponding to the stressed end of the specimen.

22 The AMA system performs the following functions: it simulates the sectional rigidity of the specimen, serves as anchorage for the prestressing strand, allows the measurement of the force supported by the strand and of the strand slip with respect to the last embedment concrete cross-section of the specimen, and enables access to increase the strand force in the 
1 anchorage loading stage. A detailed description of the test method and the AMA system

2 requirements is available in $[13,32]$.

3

\section{$4 \quad 3.1$. Testing technique}

6 The step-by-step test procedure may be summarized as follows:

7 a) Tensioning stage.

8

9

10

11

12

14

a.1) The equipment test is set up with the hydraulic jack connected to the pretensioning frame at the free end.

a.2) The prestressing strand is placed in the frame.

a.3) Two anchorage devices are put at both ends of the prestressing strand.

a.4) The prestressing strand is tensioned.

a.5) The prestressing strand is provisionally anchored by means of the adjustable strand anchorage, which is unscrewed.

a.6) The hydraulic jack is relieved (and it can be connected to other pretensioning frame for a new operation).

b) Casting of the concrete specimen.

b.1) Concrete is mixed, poured into the form positioned in the pretensionig frame, and consolidated.

b.2) The concrete specimen is cured and remains in the selected conservation conditions to achieve the desired concrete properties.

b.3) Prior to testing, the mould is relieved from the pretensioning frame.

c) Detensioning stage.

c.1) The hydraulic jack is coupled to the pretensioning frame. 

used to control the force exerted by the hydraulic jack. screwing. unloading of the hydraulic jack.

c.5) The hydraulic jack is relieved.

d) Loading stage. end.

\subsection{Instrumentation} end of the AMA system, and a hydraulic jack pressure sensor.

c.2) When the actual prestresing reinforcement force is recovered by the hydraulic jack, the adjustable strand anchorage device is relieved and withdrawn by

c.3) The strand prestress transfer is produced at a controlled speed through the

c.4) The concrete specimen is supported at the stressed end of the pretensioning frame while the prestressing force is transferred to the concrete.

d.1) The hydraulic jack is anew coupled to the pretensioning frame at the stressed

d.2) The force in the prestressing strand is increased by loading the hydraulic jack which pulls the AMA system from the pretensioning frame.

No internal measurement devices are used in order not to distort the strand-concrete bond phenomenon. Following the basis of the ECADA test method, the instrumentation is composed of a force transducer placed at the anchorage device of the prestressing strand at the 
1 Additionally, in this experimental research two displacement transducers have been used: one

2 located at the free end (Fig. 3) to measure the free end slip, and another at the stressed end

3 (Fig. 4) to measure the slip of the strand with respect to the last embedment concrete cross-

4 section of the specimen (stressed end slip).

\section{3.3. Criteria to determine transmission and anchorage lengths}

7

8 With the ECADA test method, both the transmission and the anchorage lengths are 9 determined by testing a series of specimens with different embedment lengths. The force in 10 the prestressing strand at the stressed end during both the prestress transfer process and the 11 pull-out operation is measured.

The transferred prestressing force values $\left(P_{t}\right)$ measured after the c.4 test step are arranged according to the specimen embedment length (Fig. 5). The obtained curves reveal a bilinear law. There is an ascendent initial branch and then a practically horizontal branch corresponding to the maximum possible prestressing force $\left(P_{e}\right)$. This force is determined by the bond performance and the compatibility of strains conditions, and by the properties and characteristics of the prestressing strand and concrete specimen. The transmission length $\left(L_{t}\right)$ corresponds to the shortest specimen embedment length that marks the beginning of the horizontal branch, that is, to the first specimen of the series with $P_{t}=P_{e}$.

22 For specimen embedment lengths larger than the transmission length, the force in the 23 prestressing strand is increased (d.2 test step). The pull-out force values $\left(P_{a}\right)$ achieved without 24 additional increases of the strand free end slip are arranged according to the specimen 25 embedment lengths (Fig. 5). The obtained curves present an ascending tendency. In these 
1 conditions, the anchorage length $\left(L_{a}\right)$ corresponds to the shortest embedment length of the

2 specimens that reach the $P_{r}$ force -established as a reference to analyze the anchorage

3 behavior- in the prestressing strand, that is, to the first specimen of the series with $P_{a} \geq P_{r}$.

5 Consequently, in this study the resulting length to reduce the transmission length to the 6 anchorage length $\left(L_{c}=L_{a}-L_{t}\right)$ has been defined as the complementary bond length $\left(L_{c}\right)$.

7

The characterization of the strand-to-concrete bond behavior can be completed by analysing the force-slip relationships at both ends of the test specimens during the prestress transfer process and the pull-out operation.

\section{Experimental program}

In an attempt to experimentally obtain the slip distribution in a seven-wire $13 \mathrm{~mm}$ prestressing steel strand along both the transmission and the anchorage lengths, an experimental program has been conducted. The testing equipment consisted of 6 pretensioning frames and 2 hydraulic jacks.

Test specimens had a cross-section of $100 \times 100 \mathrm{~mm}^{2}$ with a centered single strand. The prestressing strand was low-relaxation, seven-wire steel strand of $13 \mathrm{~mm}$ nominal diameter. 
1 The strand had a guaranteed ultimate strength $1860 \mathrm{MPa}$, specified as UNE 36094:97 Y 1860

$2 \quad$ S7 13.0 [37]. The manufacturer provided the following main characteristics: diameter 12.9

$3 \mathrm{~mm}$, section $99.69 \mathrm{~mm}^{2}$, nominal strength $192.60 \mathrm{kN}$, yield stress at $0.2 \% 177.50 \mathrm{kN}$, and

4 modulus of elasticity 196.70 GPa. The prestressing strand was tested in as-received conditions

5 (free of rust and free of lubricant). A prestress level of 75 percent of the nominal ultimate

6 strand strength $(1860 \mathrm{MPa})$ was applied in all cases, representative of most cases in real 7 applications.

9 Twelve concrete mixes with water/cement ratios ranging from 0.3 to 0.5 , cement contents 10 between 350 and $500 \mathrm{~kg} / \mathrm{m}^{3}$, and compressive strength at the time of testing $f^{\prime}{ }_{c i}$ from 24 to 55 $11 \mathrm{MPa}$ were tested. Concrete components were: cement CEM I 52.5 R [38], crushed limestone 12 aggregate $7 / 12$, washed rolled limestone sand $0 / 4$, and a polycarboxylic ether high range water reducer. All concretes mixes were designed with a constant gravel/sand ratio of 1.14. Concrete proportionings, concrete compressive strength values at the time of testing and the embedment lengths in the specimens tested (see Section 3) are shown in Table 1.

All specimens were subjected to the same consolidation and curing conditions. The prestress transfer was gradually performed 24 hours after casting (b.1 test step), and a 2-hour stabilization period after the prestress transfer (c.4 test step) was considered before determining the transferred prestressing force values $\left(P_{t}\right)$.

22 The loading stage (d.2 test step) was also gradually performed after the stabilization period. 23 For the anchorage analysis, a reference force $\left(P_{r}\right)$ of $158 \mathrm{kN}$ was established as representative 24 of the force that can be applied to the strand before failure in this experimental study. The 
1 pull-out operation was performed to achieve this reference force $\left(P_{r}\right)$ without strand slip at the

2 free end of the test specimen during this operation.

3

4 During the detensioning stage, and also in the loading stage, visible splitting cracks have not 5 appeared in any of the tested specimens.

\section{Results and discussion}

9 The transmission and anchorage lengths were determined for each concrete mix from series of specimens with different embedment lengths. As an example, Fig. 6 shows the results of prestressing force $\left(P_{t}\right)$ transferred to concrete and of attained pull-out forces $\left(P_{a}\right)$ versus the embedment length for specimens of concrete M-350/0.50. The results of transmission and anchorage lengths for all concrete concrete mixes are summarized in Table 2.

\subsection{Slips resulting from prestress transfer operation}

The characterization of bond behavior during the prestress transfer can be analyzed from the curves obtained [prestressing force transferred - strand end slip]. Fig. 7 shows these curves at both ends of the specimens (their embedment lengths are shown) for concrete mix M500/0.30. In the case of the test specimens with embedment length shorter than the

21 transmission length $(400 \mathrm{~mm})$, it can be observed a bilinear response with an ascendent initial

22 branch and a practically horizontal branch after a certain slip value (peak-slip). The peak-slip

23 value at the free end $\left(\delta_{f, p e a k}\right)$ and at the stressed end $\left(\delta_{s, p e a k}\right)$ correspond to the same level of 24 prestressing force transferred, resulting in the beginning of the generalized slippage of the 25 prestressing strand. The horizontal branch is longer when embedment length is shorter, and 
1 the prestressing force transferred to concrete increases when the embedment length increases

2 until it corresponds to the transmission length.

3

4 In Fig. 7 it can also be observed that the obtained curves are similar for test specimens with 5 embedment length equal to or longer than the transmission length. Slip values at both ends 6 increase progressively while the prestressing force is transferred to the concrete. In these 7 cases, a final slip value is obtained, and no peak-slip value appears.

9 As previously mentioned, the maximum strand slip after prestress transfer occurs at the free end of a specimen. The strand slip will be zero beyond the transmission length where 11 prestressing strand force does not vary with the specimen length and compatibility of strains between the prestressing strand and concrete exists. Therefore, strand slips at the stressed end should not occur in specimens with embedment lengths equal to or longer than the transmission length. However, the movements of the AMA system compounds from strand tensioning stage to detensioning (from step test procedure a.4 to c.4) imply a residual slip of 16 the strand which takes place at the stressed end. Consequently, even if the specimen embedment length is greater than the transmission length, a small slip of the strand at the stressed end is registered (see Fig. 7b).

Analysing the bond behavior from Fig.7a, the $\delta_{f, p e a k}$ values are arranged according to the specimen embedment length (shorter or equal to the corresponding transmission length) as it is shown the Fig. 8 in this particular manner: the $\delta_{f, p e a k}$ registered in a test specimen with embedment length $l$ corresponds to the strand slip in a cross section placed at a distance $l$

24 from the end of the transmission length (which is known) towards the free end of the 25 specimen. In this way for each embedment length $l$, it has been considered that the prestress 
1 transfer response is achieved when the bond capacity is exceeded. The strand slip value at a

2 distance from free end equal to 0 (also $l=400 \mathrm{~mm}$-for M-500/0.30-) corresponds to the

3 strand free end slip for the specimen embedment length equal to transmission length. This

4 distribution of $\delta_{f, p e a k}$ values results in an attempt to indirectly determine the strand slip at

5 different cross sections along the transmission length of a pretensioned prestressed concrete

6 member without distorting the bond phenomenon.

7

8 Fig. 9 shows a comparison of the strand slip distribution along the transmission length for

9 concrete mixes M-400/0.40 and M-500/0.30. As observed, strand slips are lesser for the case

10 of M-500/0.30. This fact is consistent with the higher concrete compressive strength of this

11 mix with respect to M-400/0.40, which presents greater strand slips and longer transmission 12 length.

\subsection{Equation for slip-length relationship along transmission length}

15

16

20 length.

$21 \delta_{f, x}=8.7 \frac{\left(L_{t}-x\right)^{2}}{L_{t}^{2} \sqrt{f_{c i}}}$

where $\delta_{f, \mathrm{x}}$ is the strand slip at the located section $x$ after detensioning $(\mathrm{mm}), x$ is the distance

23 of a cross section from the free end $(\mathrm{mm})$, and $f_{c i}$ is the concrete compressive strength at the 24 time of prestress transfer $(\mathrm{MPa})$. 
2 Fig. 10 shows the correlation between the predicted strand slip by applying Eq. (6) and the

3 obtained experimental results (measured $\delta_{f, p e a k}$ values). A high coefficient of correlation $R^{2}$ of $4 \quad 0.965$ has been obtained.

5

\section{$6 \quad 5.3$ Comparison with other test results and equations}

7

The theoretical values of the strand free end slip by applying Eq. (1) to Eq. (6) to the corresponding measured transmission lengh value have been obtained. In the case of the Eq. (1), the following values for the shape factor $\alpha=2, \alpha=2.44$, and $\alpha=3$ have been considered.

Fig. 11 shows the obtained ratios $\left[\delta_{f}\right.$ predicted / $\delta_{f}$ measured] -by using the proposed Eq. (6)versus the $\delta_{f}$ measured. The average value and the standard deviation of the resulting ratios and $\delta_{f}$ measured are also plotted in Fig. 11. As it can be observed, a general trend of a decreasing $\left[\delta_{f}\right.$ predicted $/ \delta_{f}$ measured] ratio when the $\delta_{f}$ measured increases exists for all the authors. As shown in Fig. 12, this trend is also observed when the strand free end slip predictions are made by Eq. (4). For the others equations, the comparisons result in an appearance as observed in Fig. 13 for Eq. (1) by sustituting $\alpha=2.44$. In these cases, the 
1 aforementioned trend by applying Eq. (6) or Eq. (4) has not been observed, and also a greater range of the $\left[\delta_{f}\right.$ predicted / $\delta_{f}$ measured $]$ ratios for a single $\delta_{f}$ measured value appears.

4 Table 3 summarizes the main results of the analyzed comparisons. The average value and the

5 standard deviation of the obtained ratios [ $\delta_{f}$ predicted / $\delta_{f}$ measured], and the percentage of 6 points that fall in the rectangle formed by the intersection of the four standard deviation lines 7 (see Figs. 11 to 13) are reported. As observed, predictions from the different equations can 8 underestimate or overestimate of experimental data. The average ratios for all results range 9 from 0.59 to 1.19 , and the standard deviation from 0.20 to 0.32 . The proposed Eq. (6) performs well with a 0.98 average ratio and the highest percentage of points falling into the 11 aforementioned rectangle (71.2\%).

\subsection{Slips resulting from pull-out operation}

The characterization of bond behavior during the loading operation can be analyzed from the obtained curves [prestressing strand force achieved - strand end slip]. Fig. 14 shows these curves at both ends of specimens (their embedment lengths are shown) for concrete mix M500/0.30. As observed for the specimen embedment lengths shorter than the transmission length $(400 \mathrm{~mm})$, strand end slips start when the pull-out force exerted by the hydraulic jack is of the order -they are slightly lower and not equal because of force losses between testing stages- of the actual prestressing strand force after detensioning (see Fig. 7). In agreement with the Stress Waves Theory [5, 42] and as shown in Fig. 14, strand end slips begin when the pull-out force exerted by the hydraulic jack is equal to the actual prestressing strand force for

24 the specimen with an embedment length equal to the transmission length. Also, only specimens with embedment length greater than the transmission length allow the prestressing 
1 strand force to increase without strand end slip. In these cases, a higher pull-out force without

2 strand end slip is achieved for a greater specimen embedment length. Finally, the specimens

3 with embedment length equal to or greater than $350 \mathrm{~mm}$ attain the $P_{r}$ force, and the strand

4 slips developed at both ends in these cases are lesser when the embedment length is greater.

5 As the specimen with $600 \mathrm{~mm}$ embedment length reachs the $P_{r}$ force without free end strand

6 slip at this test stage, $600 \mathrm{~mm}$ is the anchorage length for mix M-500/0.30 [7].

7

8 Fig. 15 illustrates the measured stressed end slip $\left(\delta_{s}\right)$ along the complementary bond length

9 for concrete mixes M-400/0.40 and M-500/0.30. These strand slips correspond to the 10 maximum stressed end slip just before free end slip at loading begins. The specimens have 11 embedment lengths ranging from the transmission length to the anchorage length. Only the complementary bond length beyond the transmission length has been illustrated (i.e. $100 \mathrm{~mm}$ in length corresponds to embedment length equal to $550+100 \mathrm{~mm}$ for M-400/0.40 and 400+100 mm for M-500/0.30). As observed, strand slips are lesser for the case of M-

500/0.30. This fact is consistent with the higher concrete compressive strength for this mix with respect to M-400/0.40. In this way, the obtained curves represent the strand slip at different cross sections along the complementary bond length of a pretensioned prestressed concrete member without distorting the bond phenomenon.

\subsection{Equation for slip-length relationship along complementary bond length}

Based on the experimental results from nine of the twelve concrete mixes (data from M450/0.4, M-500/0.35 and M-500/0.40 were unavailable for this purpose) including 35 specimens ( 9 with embedment length equal to transmission length and 26 with embedment length ranging from transmission length to anchorage length), a good adjustment to the 
1 stressed end slip values along the complementary bond length has been obtained. As a result,

2 Eq. (7) gives the strand slip distribution at every location within the complementary bond 3 length.

$4 \quad \delta_{s, x}=9 \cdot 10^{-5} \frac{\left(x-L_{t}\right)^{2}}{\sqrt{f_{c i}}}$

5 where $\delta_{s, \mathrm{x}}$ is the strand slip at the located section $x$ at loading $(\mathrm{mm}), x$ is the distance of a

6 cross section -ranging from transmission length to anchorage length- from the free end (mm), and $f_{c i}$ is the concrete compressive strength at testing time (MPa).

9 Fig. 16 shows the correlation between the predicted strand slip by applying Eq. (7) and the experimental results (measured $\delta_{s}$ values). A coefficient of correlation $R^{2}$ of 0.839 has been 11 obtained.

Results for strand slip along the complementary bond length are not available in the literature.

Therefore, it is not posible to make comparisons. Numerical simulations based on pull-out test specimens with short embedment length [6] provided a theoretical strand slip-length distribution which is qualitatively similar to the obtained in this experimental research work.

\subsection{Equation for slip-length relationship along the anchorage length}

Since the anchorage length is composed of the transmission length plus the complementary bond length, the strand slip distribution at every location within the anchorage length can be obtained by assembling the two models obtained. Fig. 17 illustrates the complete curves for concrete mixes M-400/0.40 and M-500/0.30. 


\section{6. Conclusions}

2

3 An experimental program to analyze bond behavior based on force-slip relationships and to

4 determine transmission and anchorage lengths of $13 \mathrm{~mm}$ prestressing steel strand has been

5 conducted by means of the ECADA test method. The following conclusions may be drawn

6 from this experimental research:

7 - Based on strand force-slip behavior as a function of the embedment length, a test 8 methodology to measure indirectly the strand slip at different cross sections of a

9 pretensioned prestressed concrete member without distorting the bond phenomenon has

10 been developed.

11 - The influence of concrete compressive strength on the strand slips has been analyzed: strand

12 slips are lesser for the case of higher concrete compressive strength, both at the prestress

13 transfer and pull-out (loading) stages.

14 - The following equation is proposed to predict the slip-length relationship within

15 transmission length of $13 \mathrm{~mm}$ prestressing steel strand (see notation in 5.2):

$16 \delta_{f, x}=8.7 \frac{\left(L_{t}-x\right)^{2}}{L_{t}^{2} \sqrt{f_{c i}}}$

17 - The following equation is proposed to predict the slip-length relationship within the

18 complementary bond length of $13 \mathrm{~mm}$ prestressing steel strand (see notation in 5.5):

$19 \delta_{s, x}=9 \cdot 10^{-5} \frac{\left(x-L_{t}\right)^{2}}{\sqrt{f_{c i}}}$

20 - These equations have been experimentally verified. A high coefficient of correlation $R^{2}$ of

210.965 has been obtained between predicted and measured slips for transmission length, and

220.839 for complementary bond length. 
- Regarding transmission length and free end slip of $13 \mathrm{~mm}$ prestressing steel strand, the obtained experimental results and the proposed equation have been compared with preexisting equations in the literature and with test results reported by others researchers:

- Predictions give in some cases a general trend to decrease the prediction value when the measured value increases.

- A greater range of the predicted values for a single measured value appears when the equations based on Guyon's model are used.

- A good prediction for all results has been found by using the proposed model in this work.

- An analytical bond model to predict the slip distribution of the prestressing strand at every location within the anchorage length is available by the sequential assembly of both previously proposed slip-length models.

\section{Acknowledgments}

The content of the present paper is based on tests which were conducted in the Institute of Concrete Science and Technology (ICITECH), at Universitat Politècnica of València (Spain), in collaboration with the companies PREVALESA and ISOCRON. Funding for this experimental research work was provided by the Spanish Ministry of Education and Science / Science and Innovation and ERDF (Project BIA2006-05521 and Project BIA2009-12722). The authors wish to thank the above companies as well as the concrete structures laboratory technicians at the Universitat Politècnica of València for their cooperation. Finally, the authors also wish to pay their respects to C.A. Arbeláez.

\section{References}


2 [1] FIB. Bond of reinforcement in concrete. State of the art report. Fib Bulletin $n^{\circ} 10$.

3 Lausanne: International Federation for Structural Concrete; 2000.

4 [2] ACI Committee 318. Building Code Requirements for Reinforced Concrete (ACI 318-11).

5 Farmington Hills, MI: American Concrete Institute; 2011.

6 [3] Martí-Vargas JR, Serna P, Navarro-Gregori J, Pallarés L. Bond of $13 \mathrm{~mm}$ prestressing 7 steel strands in pretensioned concrete members. Eng Struct 2012;41:403-412.

8 [4] Balázs G. Transfer control of prestressing strands. PCI J 1992;37(6):60-71.

9 [5] Martí-Vargas JR, Serna P, WM Hale. Strand bond performance in prestressed concrete 10 accounting for bond slip. Eng Struct 2013;51:236-244.

11 [6] Uijl JAd. Bond modelling of prestressing strand. In: León R, editors. Bond and 12 development of reinforcement. Farmington Hills, MI: American Concrete Institute; 1998, SP13 180, p. 145-169.

14 [7] Buckner CD. A review of strand development length for pretensioned concrete members. PCI J 1995;40(2):84-105.

[8] Zia P, Mostafa T. Development length of prestressing strands. PCI J 1977;22(5):54-65.

[9] Martí-Vargas JR, Serna P, Navarro-Gregori J, Bonet JL. Effects of concrete composition on transmission length of prestressing strands. Constr Build Mater 2012;27:350-356. Analytical model for transfer length prediction of $13 \mathrm{~mm}$ prestressing strand. Struct Eng $21 \quad$ Mech 2007;26:211-229.

22 [11] Floyd RW, Howland MB, Hale WM. Evaluation of strand bond equations for prestressed 23 members cast with self-consolidating concrete. Eng Struct 2011;33:2879-2887.

24 [12] Guyon Y. Béton précontrainte. Étude théorique et expérimentale. Paris: Ed. Eyrolles; $25 \quad 1953$. 
1 [13] Martí-Vargas JR, Serna-Ros P, Fernández-Prada MA, Miguel-Sosa PF, Arbeláez CA.

2 Test method for determination of the transmission and anchorage lengths in prestressed

3 reinforcement. Mag Concr Res 2006;58(1):21-29.

4 [14] Anderson AR, Anderson RG. An assurance criterion for flexural bond in pretensioned 5 hollow core units. ACI J 1976;73(8):457-464.

6 [15] Martí-Vargas JR, Hale WM. Predicting strand transfer length in pretensioned concrete:

7 Eurocode versus North American practice, ASCE J Bridge Eng 2013. 8 http://dx.doi.org/10.1061/(ASCE)BE.1943-5592.0000456 .

9 [16] RILEM. RPC6 Specification for the test to determine the bond properties of prestressing 10 tendons. Bagneux, France: Réunion Internationale des Laboratoires et Experts des Matériaux, 11 Systèmes de Constructions et Ouvrages; 1979.

12 [17] IRANOR. "UNE 7436: Método de ensayo para la determinación de las características de adherencia de las armaduras de pretensado. Madrid: Instituto Nacional de Racionalización y 14 Normalización; 1982.

15 [18] LCPC. Determination de la longueur conventionnelle de scellement par adherence. 16 Méthodes d'essais applicables aux armatures de précontrainte. Techniques et Méthodes n53. 17 Paris: Laboratoire Central des Ponts et Chaussées; 1999. [19] Martí-Vargas JR, Arbeláez CA, Serna-Ros P, Castro-Bugallo C. Reliability of transfer 19 length estimation from strand end slip. ACI Struct J 2007;104(4):487-494.

20 [20] Balázs G. Transfer length of prestressing strand as a function of draw-in and initial 21 prestress. PCI J 1993;38(2):86-93.

22 [21] Krishnamurthy D. A theory for the transmission length of prestressing tendons. Indian 23 Concr J 1973;2:73-80.

24 [22] Moustafa S. Pull-out strength of strand and lifting loops. Technical Bulletin 74-B5. 25 Washington: Concrete Technology Corporation; 1974. 
1 [23] Shing PB, Cooke DE, Frangopol DM, Leonard MA, McMullen ML, Hutter W. Strand

2 development and transfer length tests on high performance concrete box girders. PCI J

$32000 ; 45: 96-109$.

4 [24] Hegger J, Bülte S, Kommer B. Structural behaviour of prestressed beams made with self5 consolidating concrete. PCI J 2007;52(4):34-42.

6 [25] Vázquez-Herrero C, Martínez-Lage I, Aguilar G, Martínez-Abella F. Evaluation of 7 strand bond properties along the transfer length of prestressed lightweight concrete members. $8 \quad$ Eng Struct 2013;49:1048-1058.

9 [26] Mahmoud ZI, Rizkalla SH, Zaghloul ER. Transfer and development lengths of carbon 10 fiber reinforcement polymers prestressing reinforcing. ACI Struct J 1999;96(4):594-602.

11 [27] Mains RH. Bond stresses in prestressed concrete from x-ray photographs. P I Civ Eng $12 \quad 1955 ; 14(1): 212-235$.

13 [28] Ratz EH, Holmjanski MM, Kolner VM. The trasnsmission of prestress to concrete by 14 bond. Berlín: Fédération Internationale de la Précontrainte; 1958, Session III, p. 624-640.

15 [29] Levis ADM, More JH. Linear-movement air gage for detection of concrete-bond failure. 16 Exp Mech 1962;2(11):335-337.

17 [30] Evans RH, Robinson WR. Bond stresses in prestressed concrete from x-ray photographs. P I Civ Eng 1955;14(1):212-235.

19 [31] Arun B, Kesavan K, Parivallal S, Ravisankar K. Technique for instrumentation and 20 measurement of interfacial strains in FRP strengthened concrete structures using FBG 21 sensors. Exp Tech 2011;35(4):35-38.

22 [32] Martí-Vargas JR, Caro LA, Serna P. Experimental technique for measuring the long-term 23 transfer length in prestressed concrete. Strain 2013;49:125-134. 
1 [33] Martí-Vargas JR, Arbeláez CA, Serna-Ros P, Fernández-Prada, MA, Miguel-Sosa PF.

2 Transfer and development lengths of concentrically prestressed concrete. PCI J $3 \quad 2006 ; 51(5): 74-85$.

4 [34] Caro LA, Martí-Vargas JR, Serna P. Time-dependent evolution of strand transfer length 5 in pretensioned prestressed concrete members. Mech Time-Depend Mater 2012. 6 http://dx.doi.org/10.1007/s11043-012-9200-2.

7 [35] Caro LA, Martí-Vargas JR, Serna P. Prestress losses evaluation in prestressed concrete 8 prismatic specimens. Eng Struct 2013;48:704-715.

9 [36] Martí-Vargas JR, Serna-Ros P, Arbeláez CA, Rigueira-Victor JW. Bond behaviour of 10 self-compacting concrete in transmission and anchorage. Mater Constr 2006;56(284):27-42.

11 [37] AENOR. UNE 36094:1997 Alambres y cordones de acero para armaduras de hormigón 12 pretensado. Madrid: Asociación Española de Normalización y Certificación; 1997.

13 [38] CEN. Cement. Part 1: Compositions, specifications and conformity criteria for common 14 cements. European standard EN 197-1:2000. Brussels: Comité Européen de Normalisation; 152000.

16 [39] Russell BW, Burns NH. Measured transfer lengths of 0.5 and 0.6 in. strands in 17 pretensioned concrete. PCI J 1996;41(5):44-65.

18 [40] Rose DR, Russell BW. Investigation of standarized tests to measure the bond 19 performance of prestressing Strand. PCI J 1997;42(4):56-80.

20 [41] Oh BH, Kim ES. Realistic evaluation of transfer lengths in pretensioned, prestressed 21 concrete members. ACI Struct J 2000;97(6):821-830.

22 [42] Janney J. Nature of bond in pretensioned prestressed concrete. ACI J 1954;25(9):71723737. 


\section{Table 1}

Concrete mixture designs and specimen embedment lengths tested

\begin{tabular}{|c|c|c|c|c|c|}
\hline Designation & $\begin{array}{l}\text { cement } \\
\left(\mathrm{kg} / \mathrm{m}^{3}\right)\end{array}$ & $\begin{array}{l}\text { water/cement } \\
\text { ratio }\end{array}$ & $\begin{array}{c}f_{c i} \\
(\mathrm{MPa})\end{array}$ & $\begin{array}{l}f_{c, 28} \\
(\mathrm{MPa})\end{array}$ & $\begin{array}{c}\text { specimen } \\
\text { embedment length }(\mathrm{mm})\end{array}$ \\
\hline C-350-0.50 & \multirow{3}{*}{350} & 0.50 & 26.1 & 50.7 & $\begin{array}{c}400 / 450 / 500 / 550 / 600 / 650 / \\
/ 700 / 750 / 800 / 850 / 900\end{array}$ \\
\hline C-350-0.45 & & 0.45 & 37.3 & 61.5 & $450 / 500 / 550 / 600 / 650 / 700$ \\
\hline C- $350-0.40$ & & 0.40 & 46.7 & 69.2 & $450 / 500 / 550 / 600 / 650 / 700$ \\
\hline C-400-0.50 & \multirow{4}{*}{400} & 0.50 & 24.2 & 42.8 & $\begin{array}{c}500 / 550 / 600 / 650 / 700 / 750 / \\
/ 800 / 850 / 900 / 950 / 1000 / 1050\end{array}$ \\
\hline C-400-0.45 & & 0.45 & 28.3 & 50.2 & $450 / 500 / 550 / 600 / 650 / 700$ \\
\hline C- $400-0.40$ & & 0.40 & 41.4 & 66 & $\begin{array}{c}250 / 350 / 400 / 450 / 500 / 550 / 600 / \\
/ 700 / 850 / 1350\end{array}$ \\
\hline C-400-0.35 & & 0.35 & 45.3 & 75.3 & $\begin{array}{l}350 / 400 / 450 / 500 / 550 / 600 / \\
/ 650 / 700 / 750 / 800 / 850 / 900\end{array}$ \\
\hline C- $450-0.40$ & \multirow{2}{*}{450} & 0.40 & 36.3 & 65.2 & $\begin{array}{l}350 / 400 / 450 / 500 / 550 / 600 / \\
/ 650 / 700 / 750 / 800 / 850 / 900\end{array}$ \\
\hline C-450-0.35 & & 0.35 & 46.6 & 73.6 & $\begin{array}{c}350 / 400 / 450 / 500 / 550 / 600 / \\
650 / 700 / 750 / 800 / 850 / 900\end{array}$ \\
\hline C-500- 0.40 & \multirow{3}{*}{500} & 0.40 & 30.8 & 59.2 & $\begin{array}{c}350 / 450 / 500 / 550 / 600 / 650 / \\
/ 700 / 750 / 800 / 900 / 1000\end{array}$ \\
\hline C-500-0.35 & & 0.35 & 46.6 & N.A. & $350 / 400 / 450 / 500 / 550 / 600$ \\
\hline C-500-0.30 & & 0.30 & 54.8 & N.A. & $\begin{array}{c}50 / 100 / 150 / 200 / 250 / 300 \\
/ 350 / 400 / 450 / 500 / 550 / 600\end{array}$ \\
\hline
\end{tabular}


Table 2

Transmission and anchorage length results

\begin{tabular}{lccc}
\hline Designation & $\begin{array}{c}\text { Transmission length } \\
(\mathrm{mm})\end{array}$ & $\begin{array}{c}\text { Anchorage length } \\
(\mathrm{mm})\end{array}$ & $\begin{array}{c}\text { Complementary } \\
\text { bond length }(\mathrm{mm})\end{array}$ \\
\hline C-350-0.50 & 550 & 650 & 100 \\
C-350-0.45 & 550 & 700 & 150 \\
C-350-0.40 & 550 & 700 & 150 \\
\hline C-400-0.50 & 650 & 850 & 200 \\
C-400-0.45 & 550 & 700 & 150 \\
C-400-0.40 & 550 & 700 & 150 \\
C-400-0.35 & 500 & 600 & 100 \\
\hline C-450-0.40 & 550 & 700 & 150 \\
C-450-0.35 & 500 & 650 & 150 \\
\hline C-500-0.40 & 600 & 800 & 200 \\
C-500-0.35 & 450 & 600 & 150 \\
C-500-0.30 & 400 & 600 & 200 \\
\hline
\end{tabular}




\section{Table 3}

Summary of predicted/measured ratios from comparisons of test results and equations

\begin{tabular}{|c|c|c|c|c|c|c|c|c|c|c|c|c|}
\hline & & \multicolumn{8}{|c|}{ Experimental data source } & \multirow{2}{*}{\multicolumn{2}{|c|}{ All data }} & \multirow{3}{*}{$\begin{array}{c}\% \text { points into } \\
\text { the defined } \\
\text { rectangles }\end{array}$} \\
\hline \multirow{2}{*}{\multicolumn{2}{|c|}{ Equation source }} & \multicolumn{2}{|c|}{$\begin{array}{l}\text { Russell and Burns } \\
\text { (1996) [41] }\end{array}$} & \multicolumn{2}{|c|}{$\begin{array}{c}\text { Rose and Russell } \\
\text { (1997) [42] }\end{array}$} & \multicolumn{2}{|c|}{$\begin{array}{c}\text { Oh and Kim } \\
(2000)[43] \\
\end{array}$} & \multicolumn{2}{|c|}{ Test results } & & & \\
\hline & & Average & S.D. & Average & S.D. & Average & S.D. & Average & S.D. & Average & S.D. & \\
\hline \multirow{3}{*}{ Eq. (1) [12] } & $\alpha=2$ & 2.41 & 0.33 & 1.25 & 0.16 & 1.97 & 0.14 & 1.92 & 0.25 & 1.18 & 0.30 & 63.7 \\
\hline & $\alpha=2.44$ & 1.98 & 0.27 & 1.02 & 0.13 & 1.62 & 0.11 & 1.57 & 0.21 & 0.96 & 0.25 & 63.7 \\
\hline & $\alpha=3$ & 1.61 & 0.22 & 0.83 & 0.11 & 1.31 & 0.09 & 1.28 & 0.17 & 0.78 & 0.20 & 63.7 \\
\hline \multicolumn{2}{|l|}{ Eq. (2) [4] } & 2.01 & 0.35 & 0.31 & 0.09 & 1.35 & 0.23 & 0.96 & 0.15 & 0.59 & 0.26 & 69.8 \\
\hline \multicolumn{2}{|l|}{ Eq. (3) [20] } & 1.87 & 0.25 & 0.63 & 0.11 & 1.44 & 0.14 & 1.26 & 0.17 & 0.76 & 0.24 & 65.1 \\
\hline \multicolumn{2}{|l|}{ Eq. (4) [4] } & 1.84 & 0.34 & 1.90 & 0.29 & 1.59 & 0.12 & 1.82 & 0.25 & 1.19 & 0.32 & 68.4 \\
\hline \multicolumn{2}{|c|}{ Eq. (5) [21] } & 1.83 & 0.27 & 0.48 & 0.11 & 1.27 & 0.17 & 1.05 & 0.16 & 0.64 & 0.22 & 71.2 \\
\hline \multicolumn{2}{|c|}{ Eq. (6) proposed } & 1.56 & 0.29 & 1.63 & 0.25 & 1.39 & 0.10 & 0.98 & 0.19 & 0.98 & 0.26 & 71.2 \\
\hline
\end{tabular}

Note: S.D. is standard deviation 


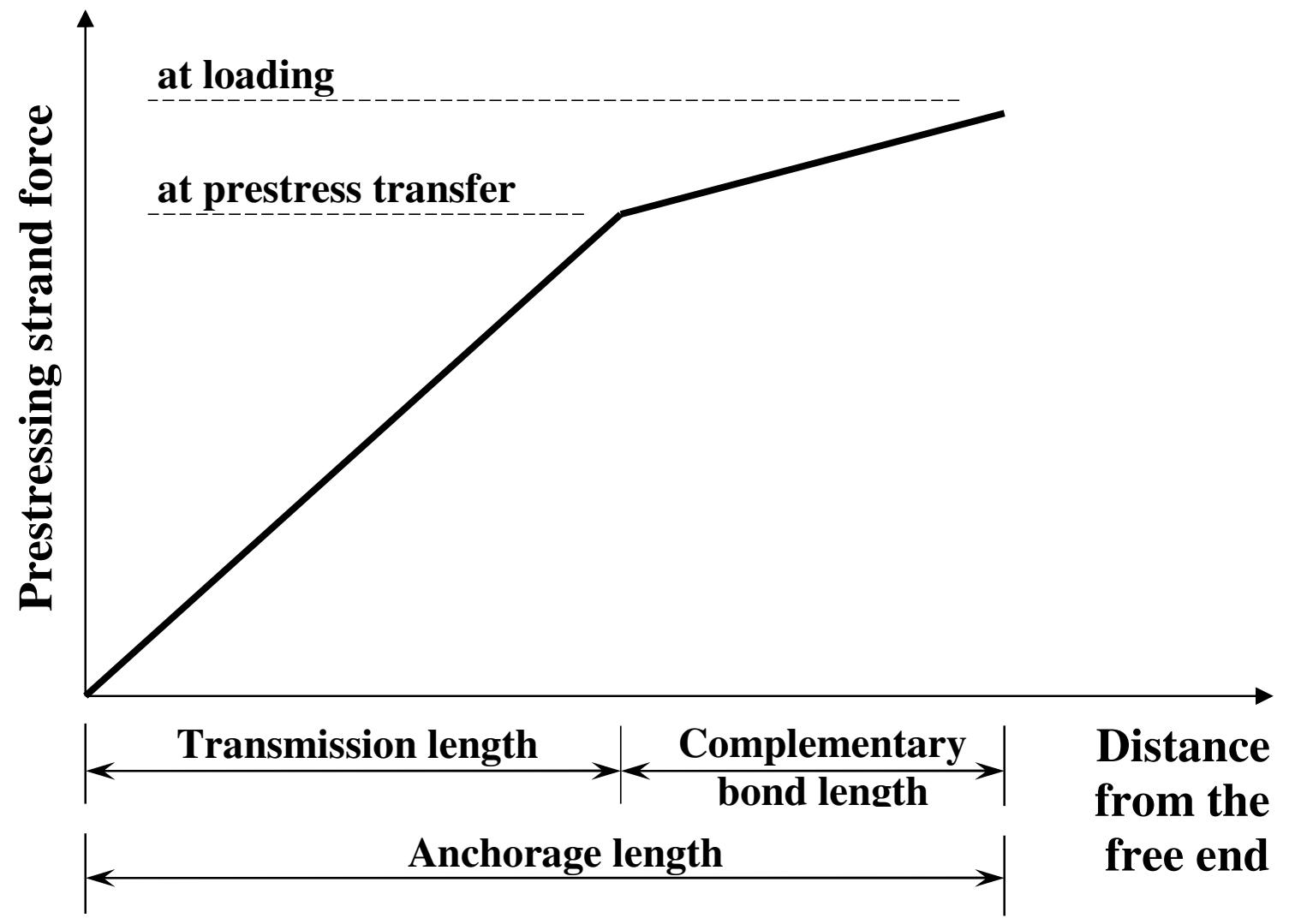




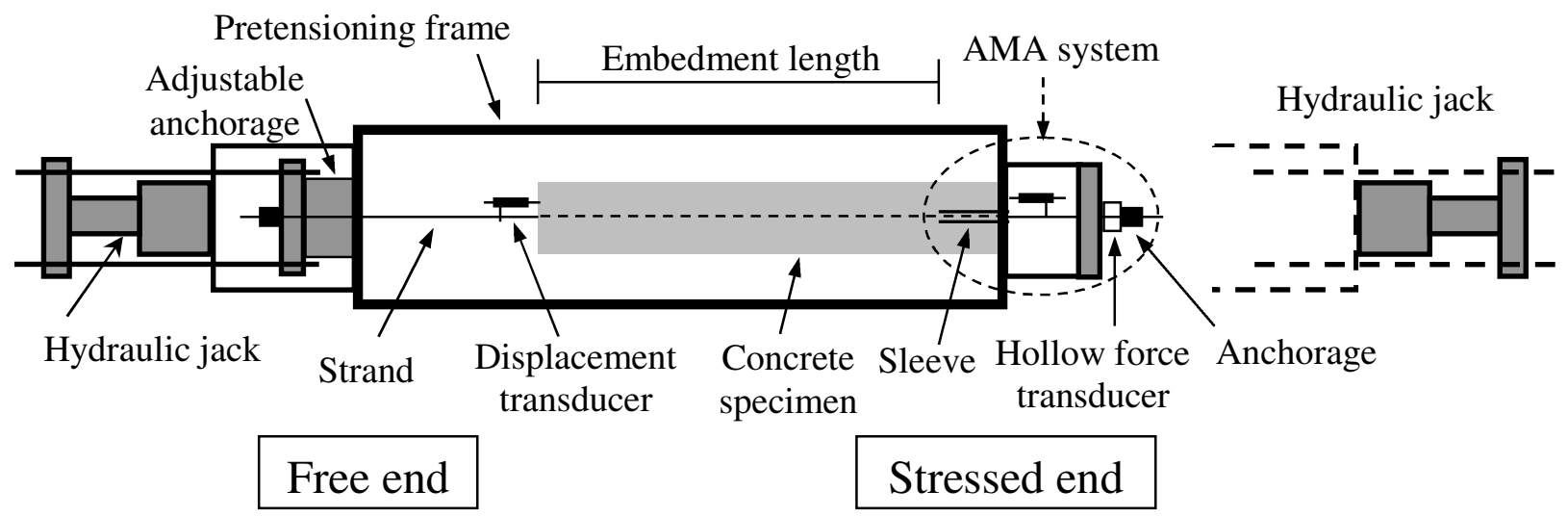




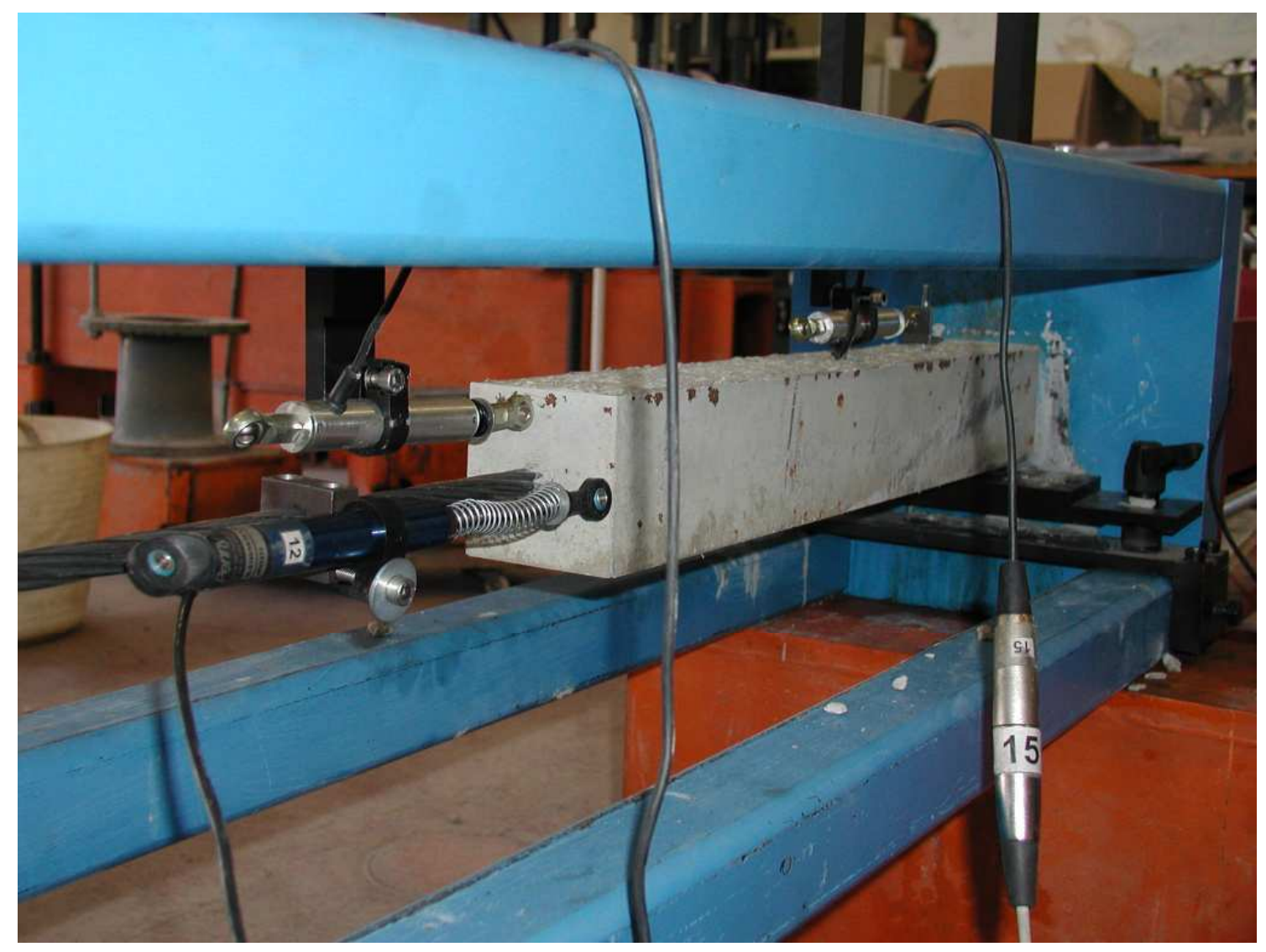




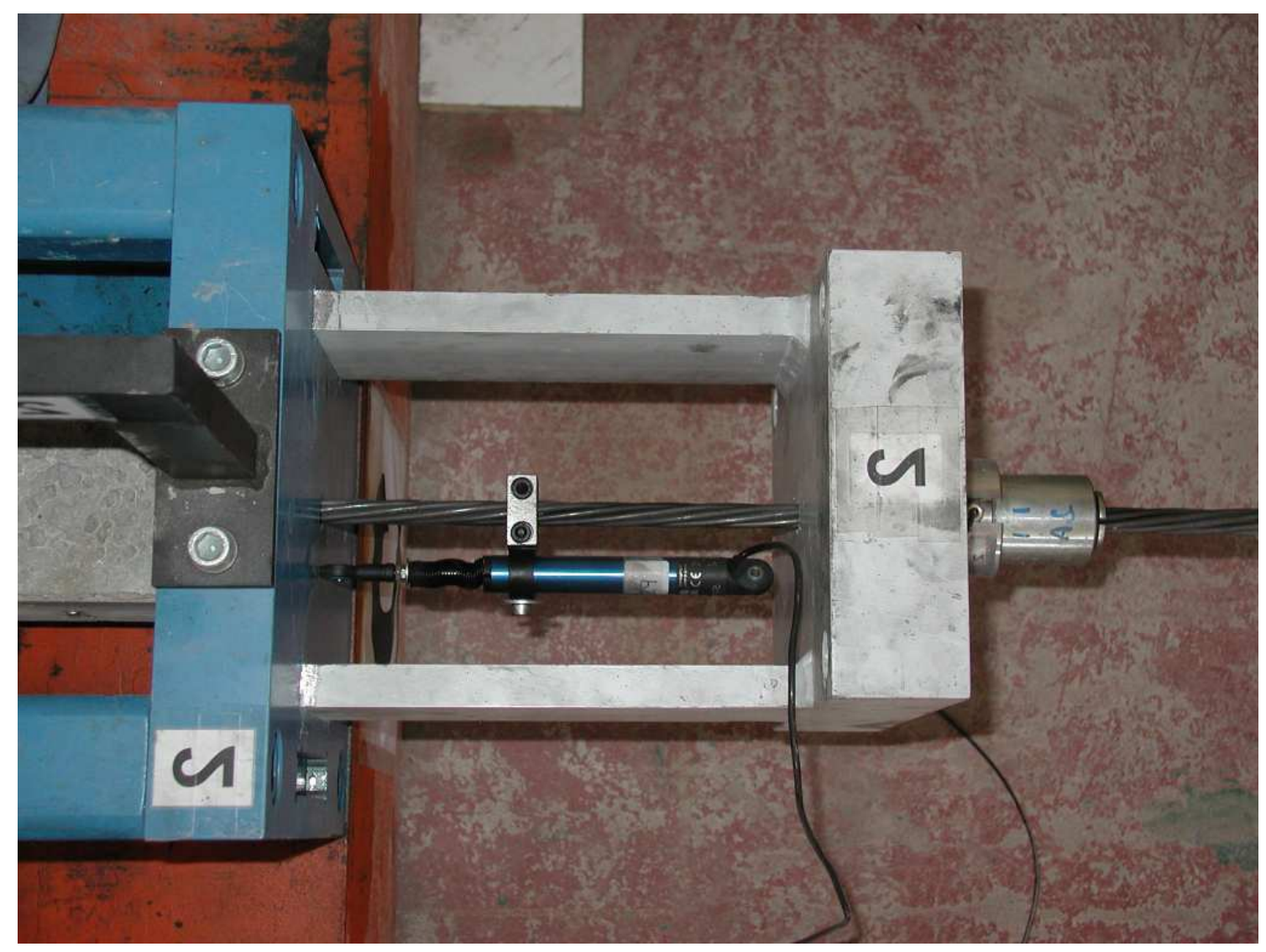




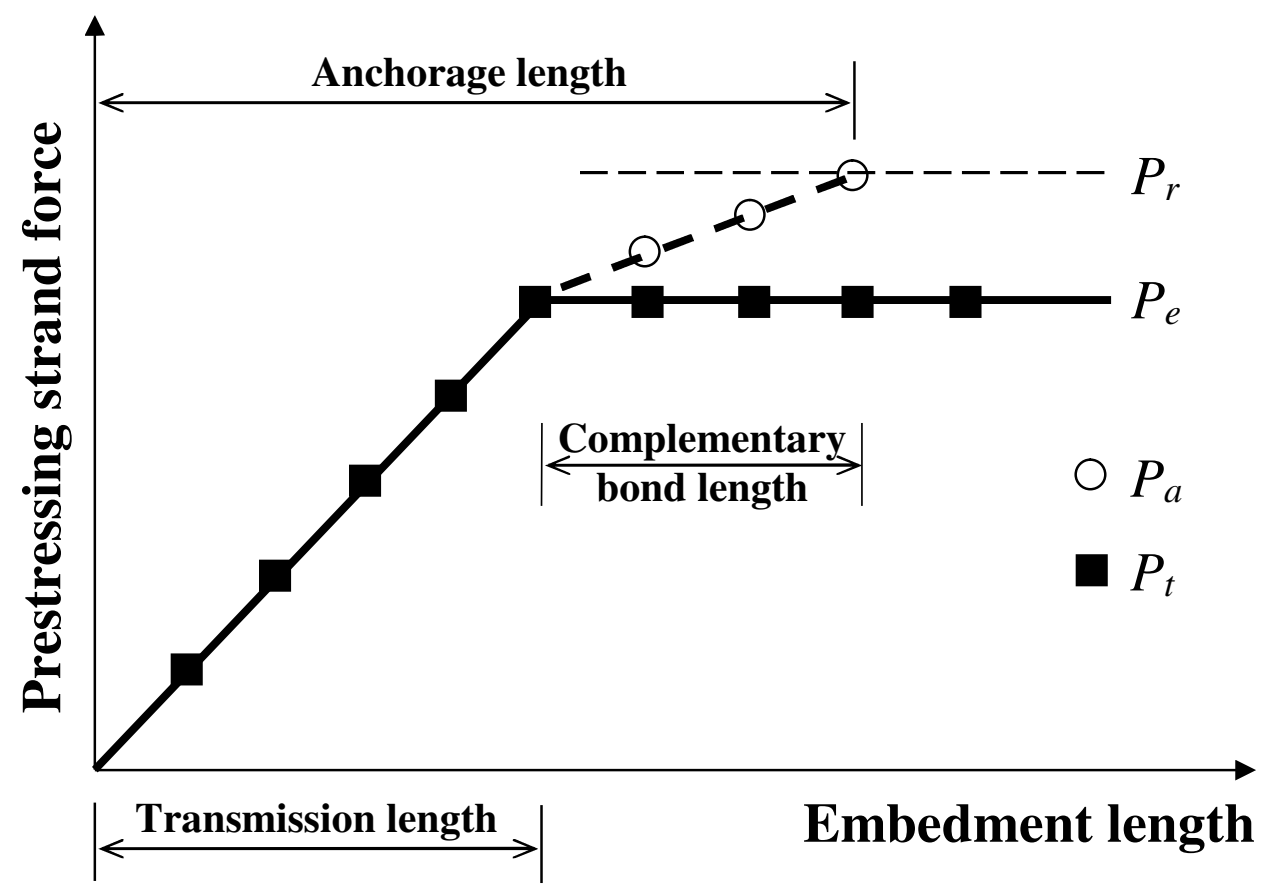




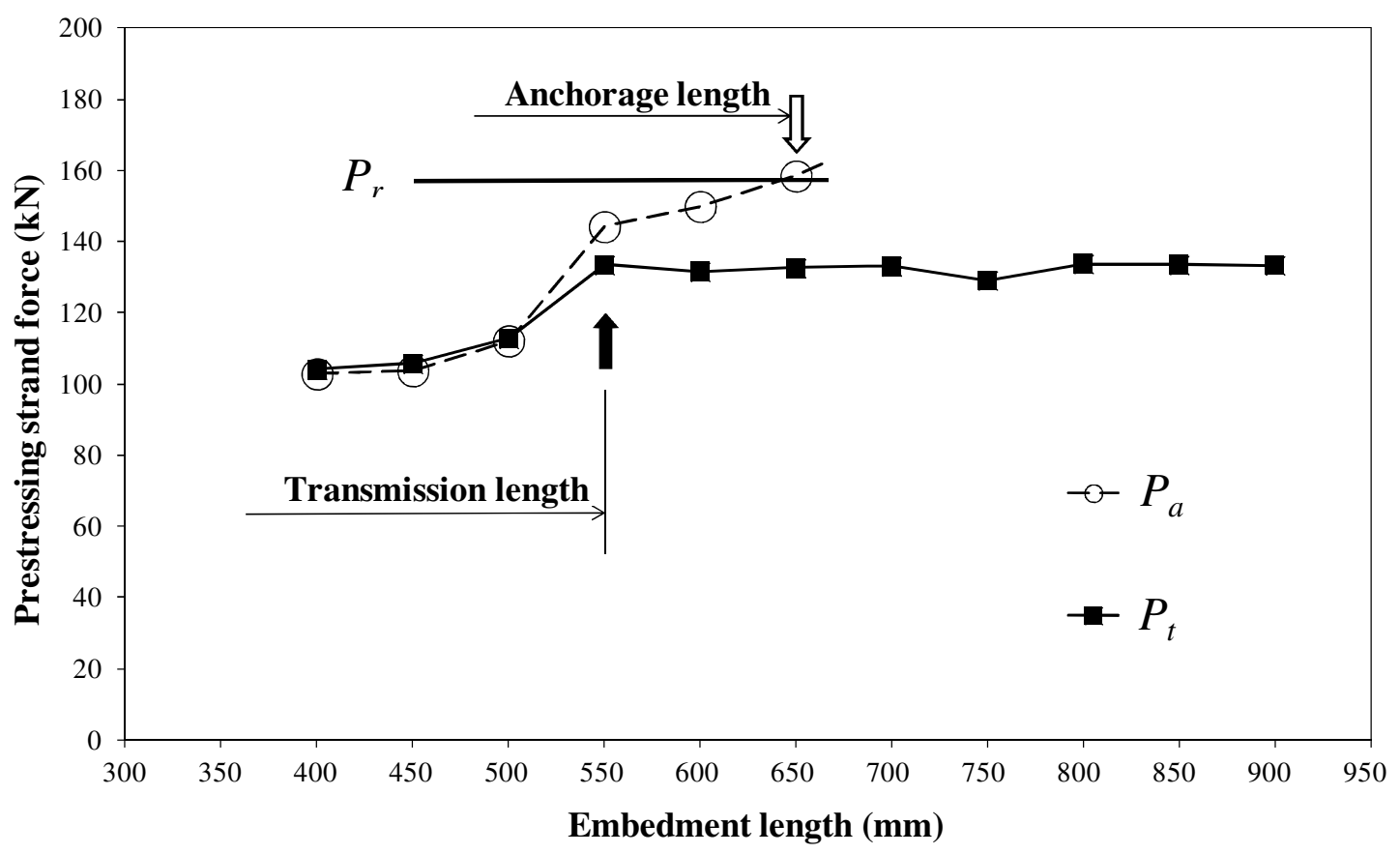




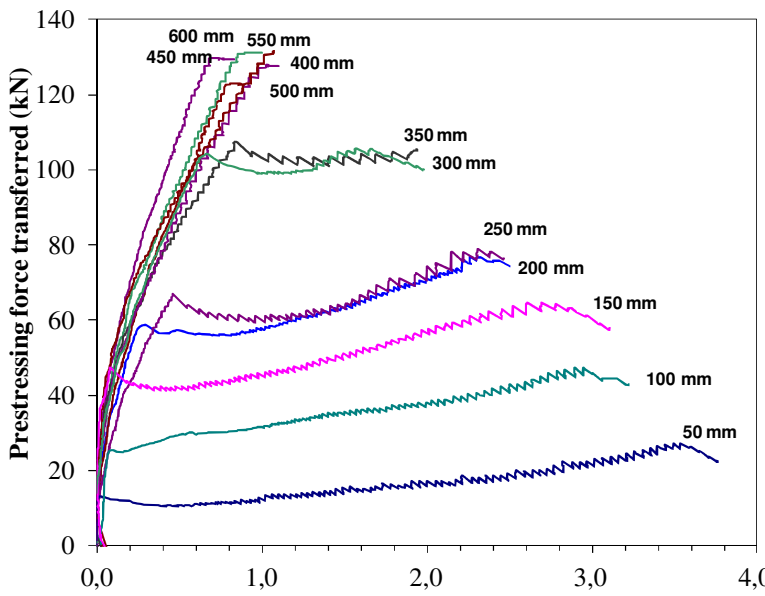

(a) Free end slip $\left(\delta_{f}\right)(\mathrm{mm})$

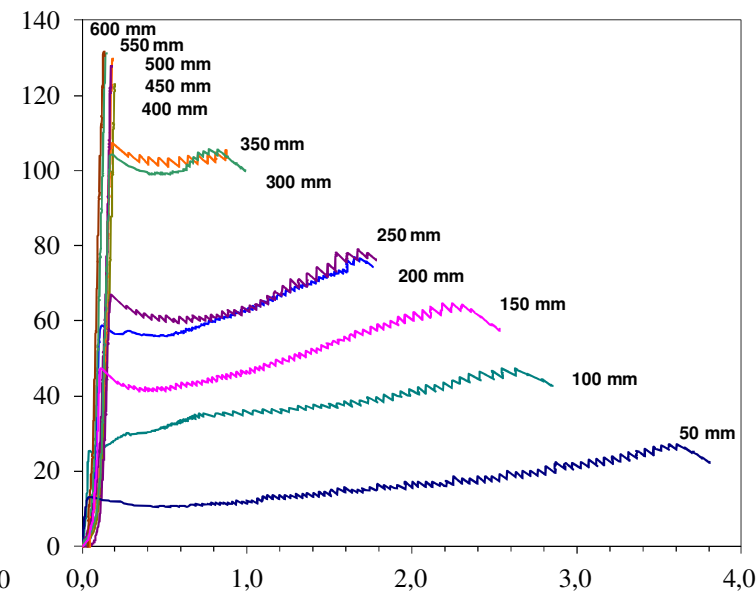

(b) Stressed end slip $\left(\delta_{s}\right)(\mathbf{m m})$ 


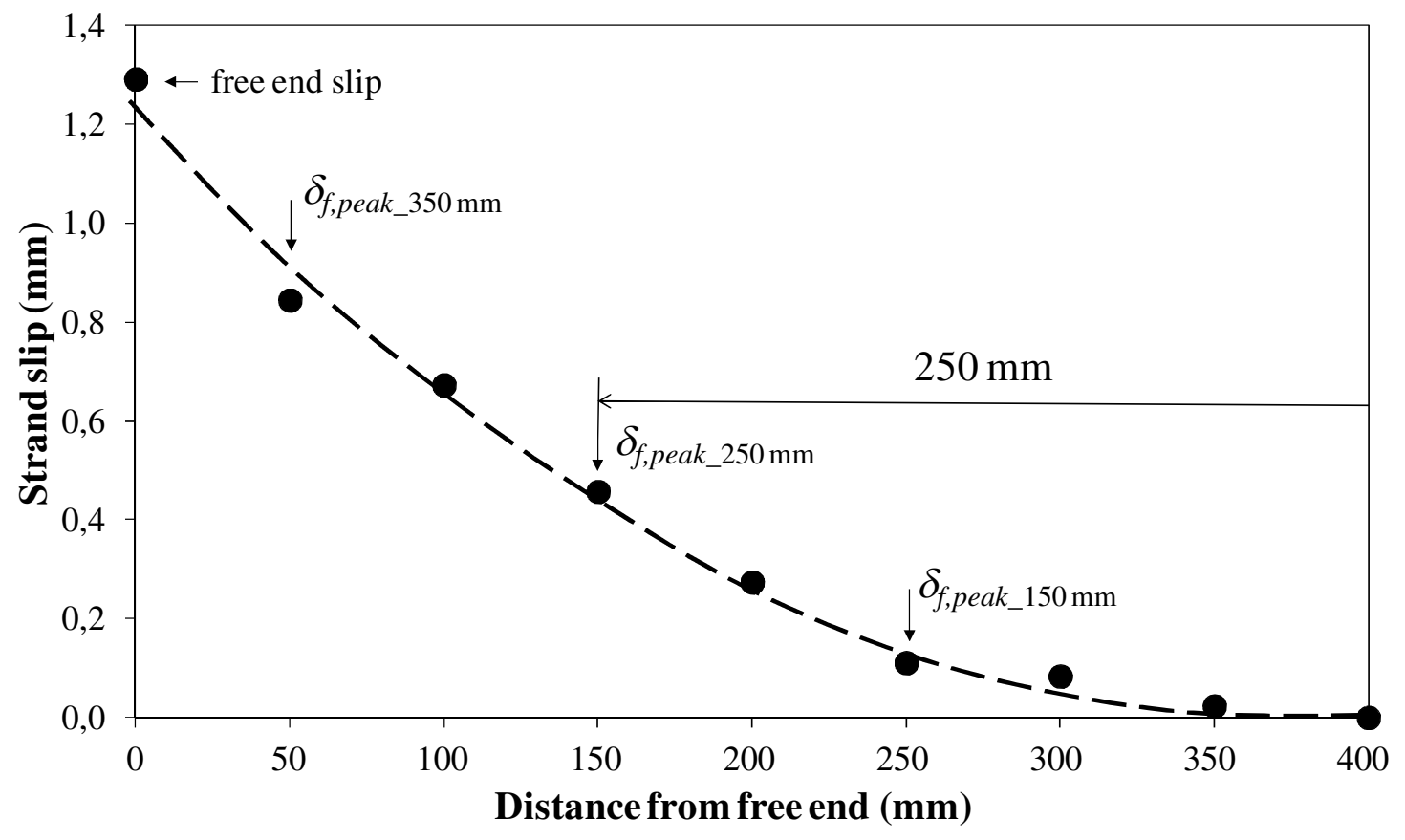




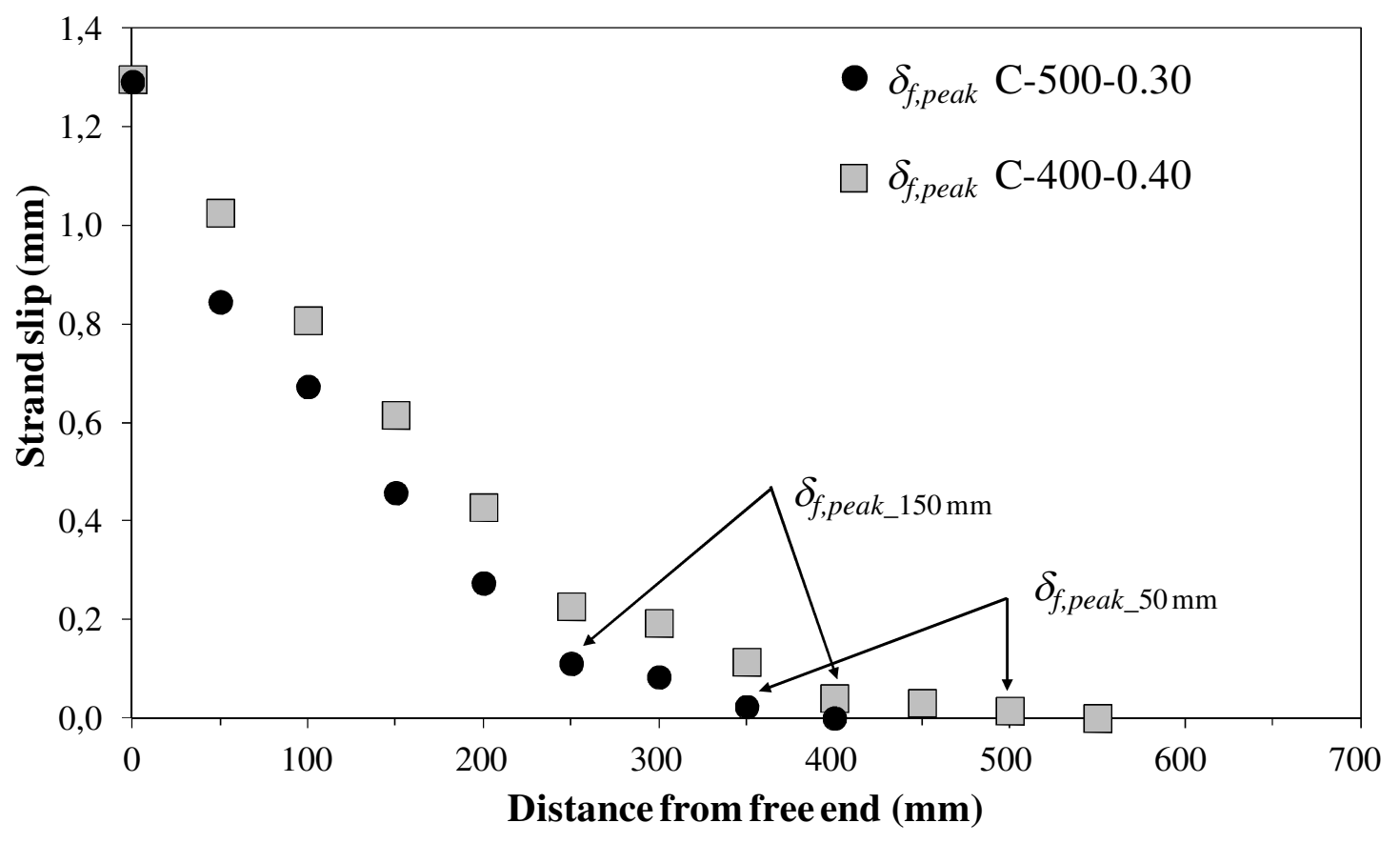




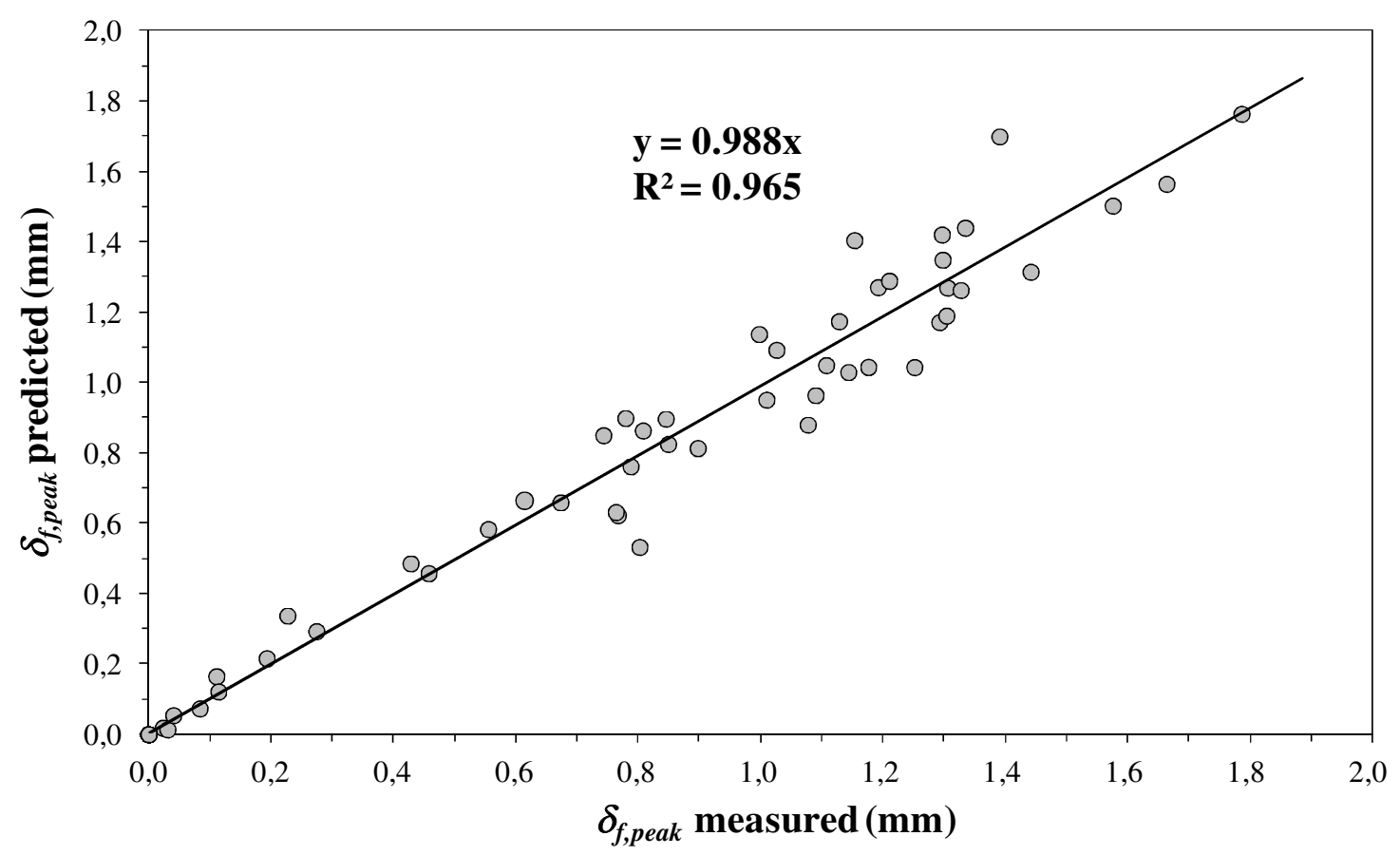




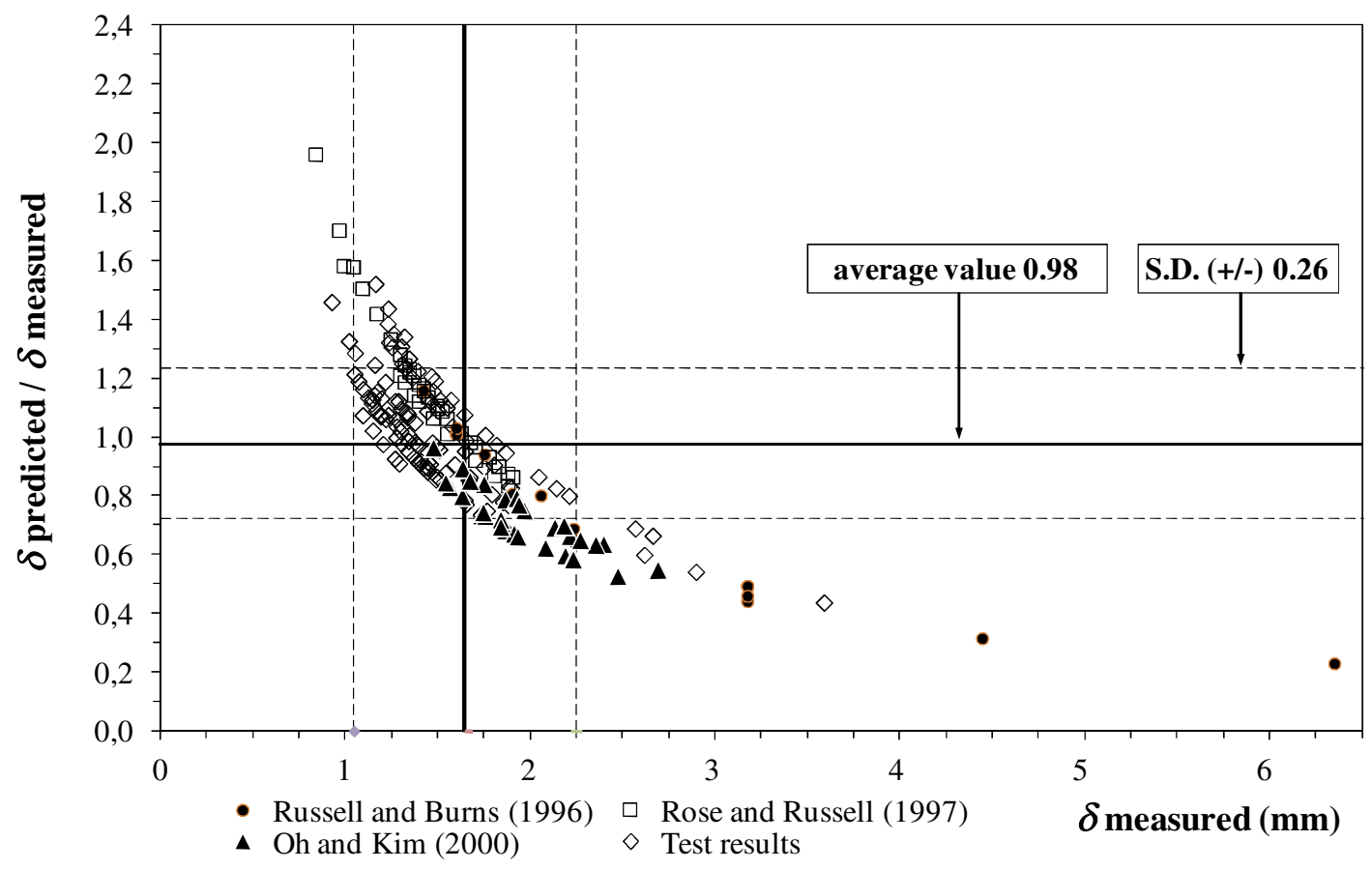




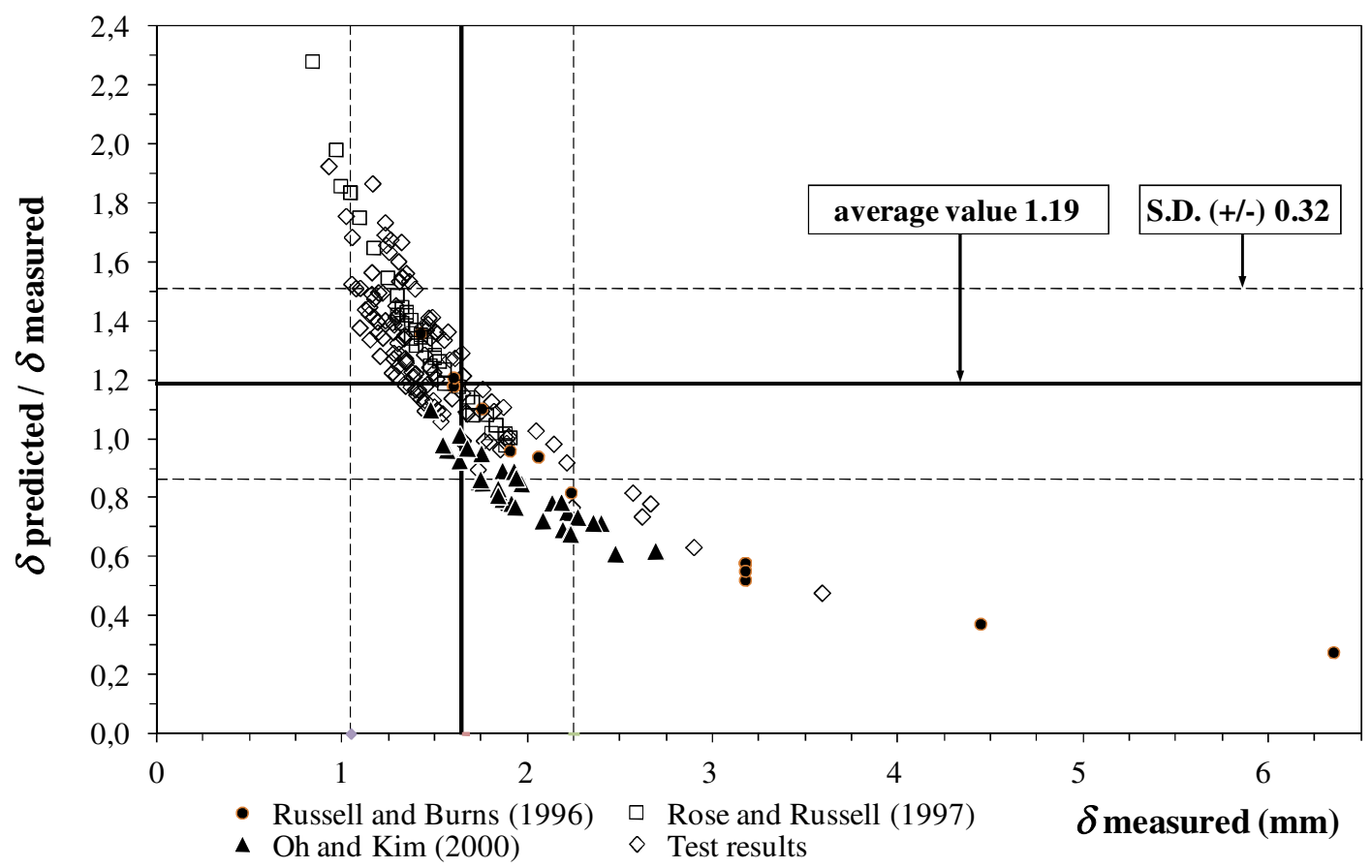




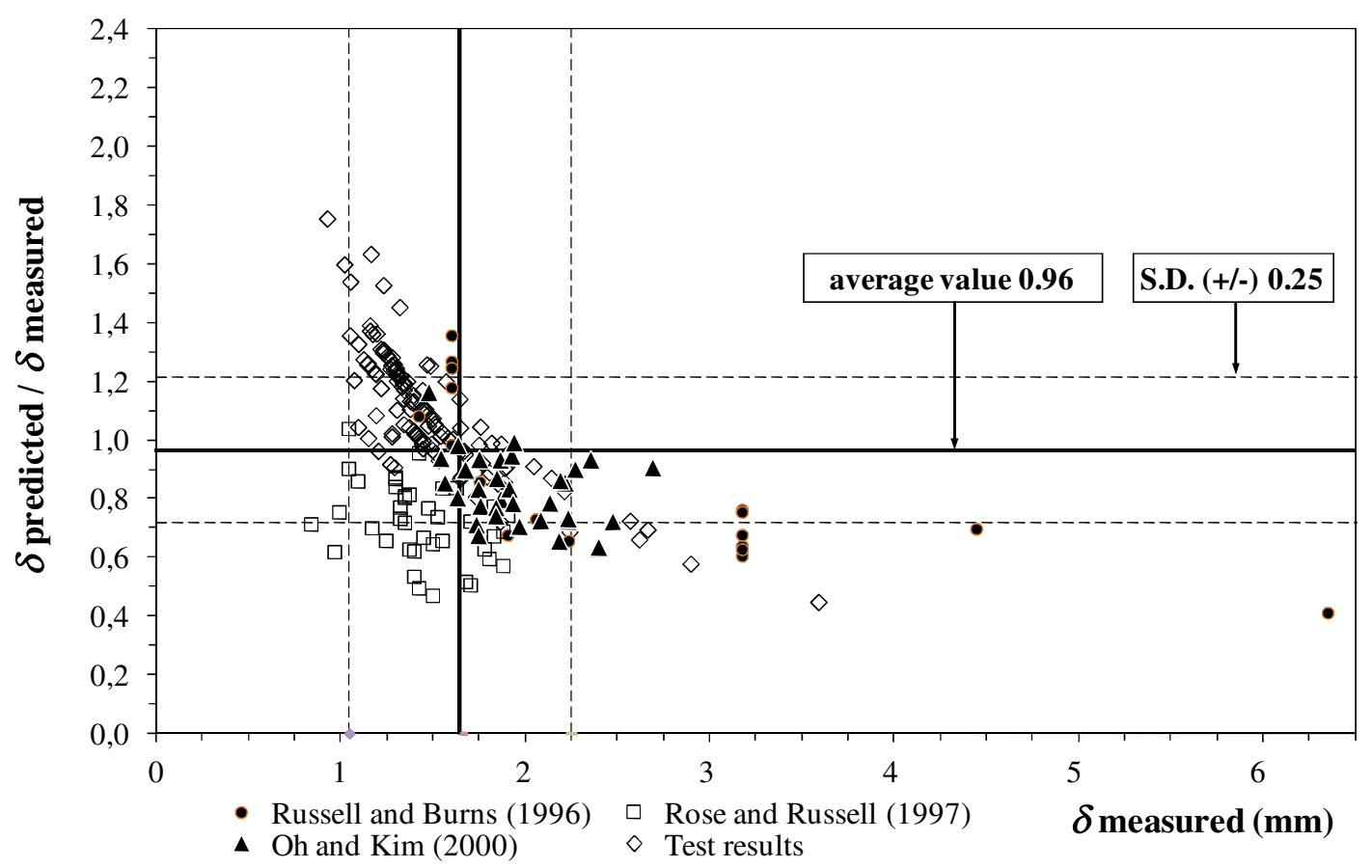




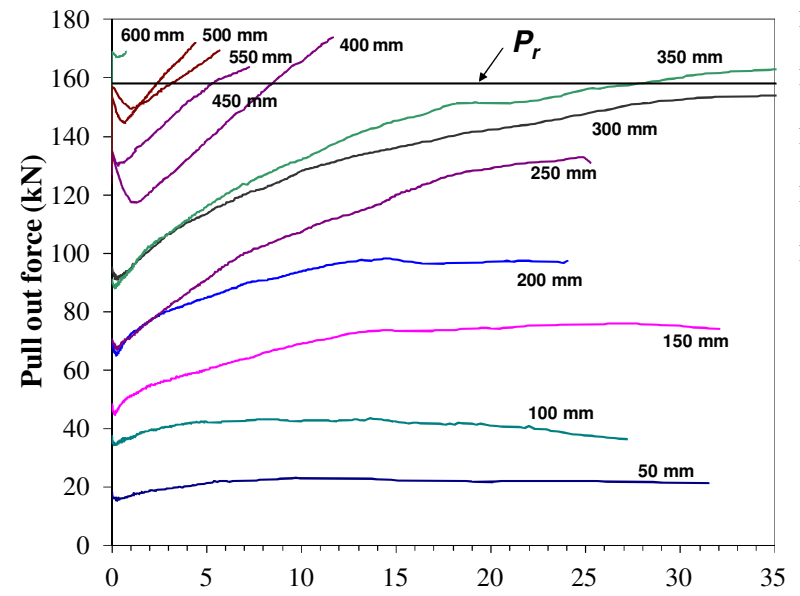

(a) Free end slip $\left(\delta_{f}\right)(\mathrm{mm})$

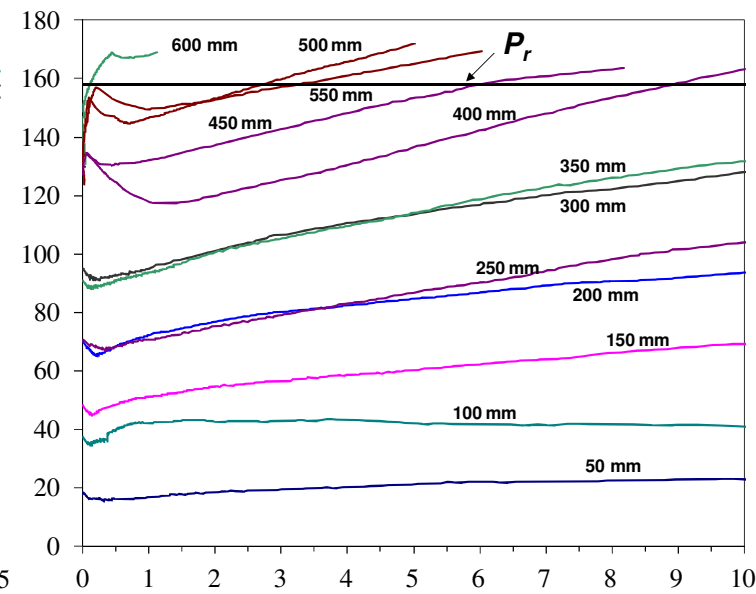

(b) Stressed end slip $\left(\delta_{s}\right)(\mathrm{mm})$ 


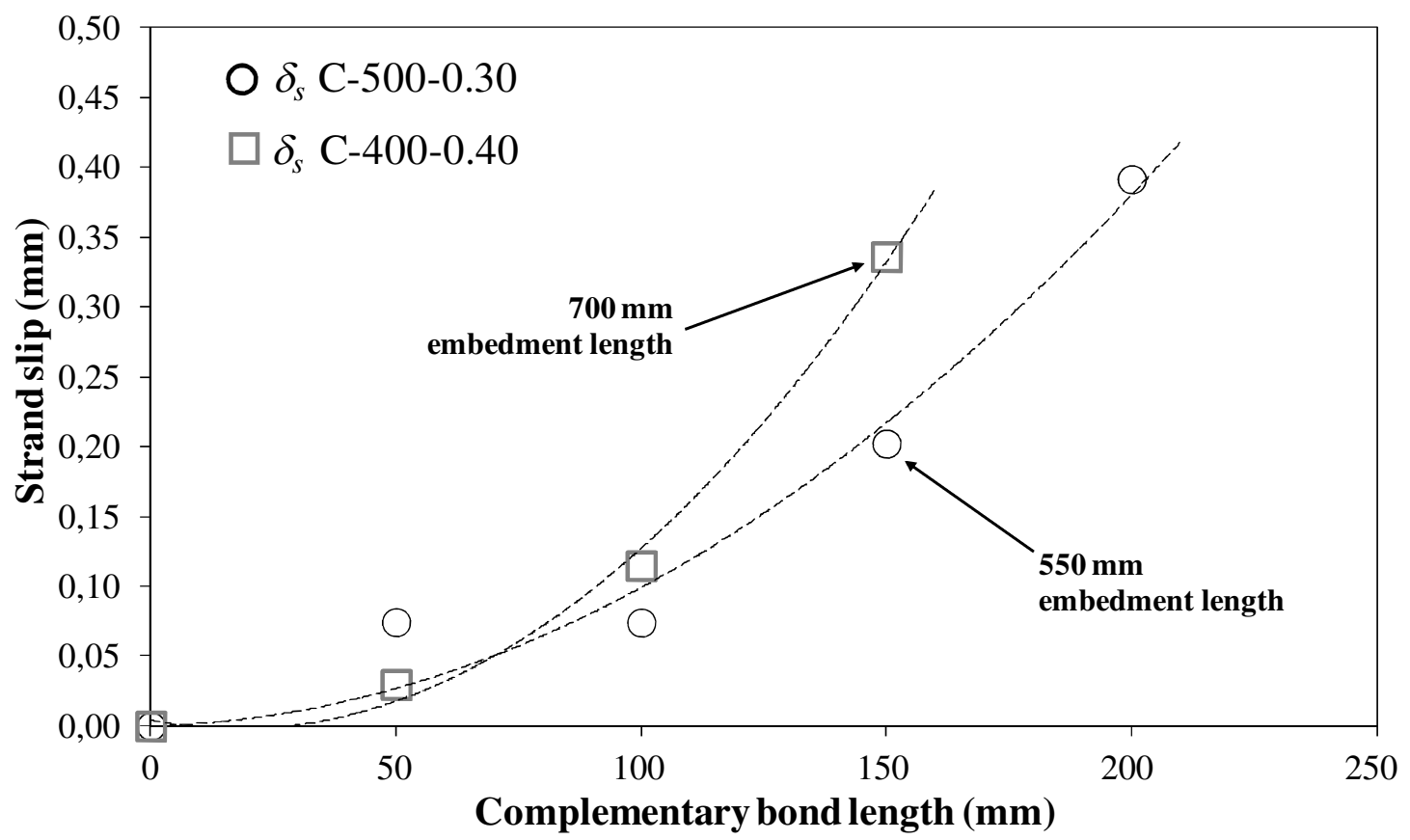




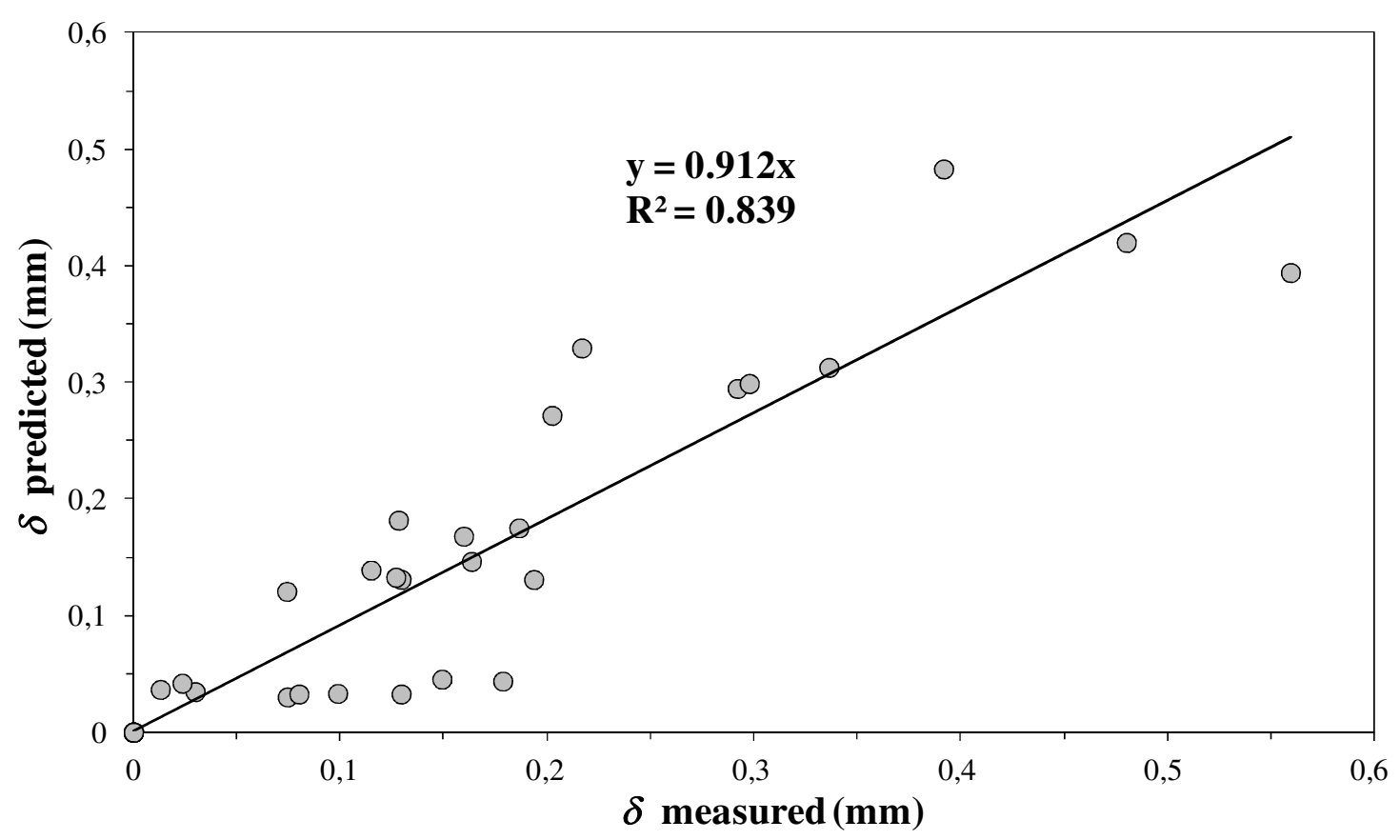




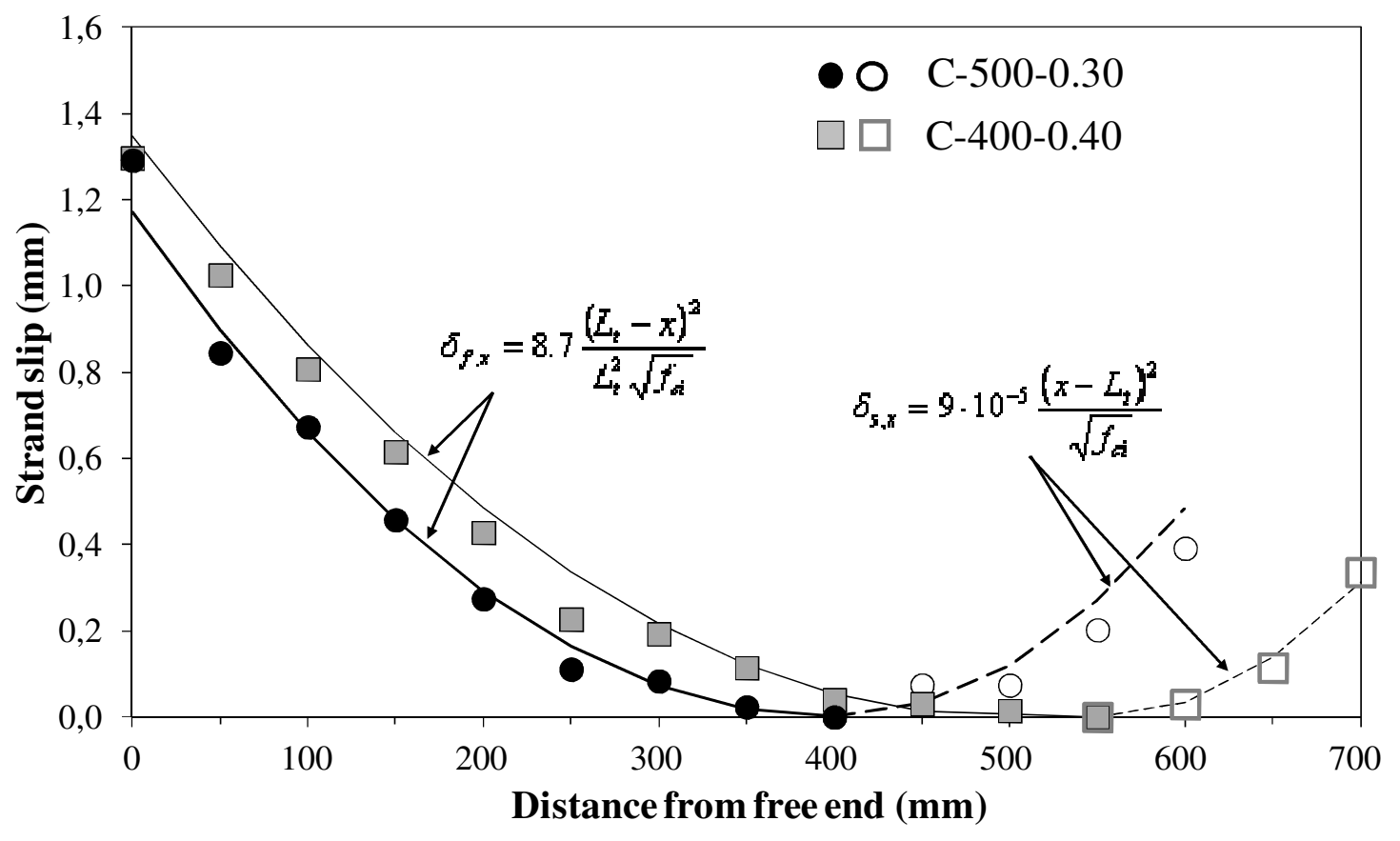

